\title{
DESIGNING DISTANCE LEARNING MATERIALS USING A DIALOGIC THEORY OF LANGUAGE
}

Yusef Waghid

University of Stellenbosch

This article deals with a dialogic theory of language as the guiding principle for learnercentred and interactive distance learning course materials. Constituted by the power of dialogue, a dialogic theory of language is used to develop an understanding of instructional design that embodies dynamism and flexibility. Such a notion of instructional design should engender practices that can bring about learner-centred course materials for distance learning.

Hierdie artikel het te make met 'n dialogiese taalteorie wat as orienteringsbeginsel dien vir leer-gesentreerde en interaktiewe kursusmateriaal van afstandsleer. 'n Dialogiese taalteorie wat gekonstitueer word deur die mag van dialoog word gebruik om 'n begrip van instruksionele ontwerp te ontwikkel, wat dinamika en aanpasbaarheid omvat. Hierdie tipe instruksionele ontwerp behoort praktyke te kan genereer wat leer-gesentreerde kursusmateriaal vir afstandleer bewerkstellig.

\section{INTRODUCTION}

The main line of argument put forward in this article is that learner-centred, interactive distance learning material can be achieved, if guided by a dialogic theory of language. In turn, a dialogic theory of language guides and shapes a dynamic and flexible method of instructional design (ID) which can effect learner-centred distance course materials.

First, the article addresses the question as to what a dialogic theory of language is. Secondly, I explain a learner-centred pedagogy within distance learning drawing on my own experiences in the field. Finally I show how a dialogic theory of language can bring about a dynamic and flexible system of course design.

\section{DIALOGIC THEORY OF LANGUAGE}

Central to the design and development of distance learning materials for learners of higher education, is a pedagogy with a learner-centred approach. This notion of learnercentredness in distance learning is described by Moore (1990:12) as 'a family of transactions between teachers and learners'. These 'transactions' include two dimensions: First, dialogue and structure and, second, learner autonomy (Moore, 1990:10-11). The idea of 'dialogue and structure' as one dimension grows out of the works of Wedemeyer (1971). Dialogue refers to the extent to which the learner and teacher respond to each other in 
relation to the content of subject-matter studied, educational philosophy of teacher, personalities of teacher and learner, environmental factors and medium of communication. Structure expresses the responsiveness of educational theory, teaching methodologies, and evaluation measures of distance learning to the needs of the learner (Wedemeyer in Moore, 1990:10). In a dialogic theory of language, the power of dialogue not only shapes the relationship between teacher and learner at a distance, but also adapts the distance learning materials to the individual needs of the learner.

Second, learner autonomy describes the 'extent to which in a (distance learning) program the learner determines objectives, implementation procedures, and resources and evaluation' (Moore, 1990:13): In other words, autonomy depicts the extent to which learners exercise responsibility over the learning process. The upshot of this 'transaction' between teacher and learner is that learner-centredness in distance learning cannot be achieved if the self-understanding of both teacher and learner is not invoked in distance pedagogy. In essence, dialogue and learner autonomy are central to the learner-centredness of distance learning. I shall now tease out the notion of a dialogic theory of language to make sense of the idea leading to learner-centredness in distance learning.

Bakhtin (1981:232) in The Dialogic Imagination posits that 'all language (in this instance, the language of distance learning materials) is dialogic'. For him in a dialogic theory of language the author's (teacher's) word answers, anticipates, interrogates, affirms, resists, or builds onto another's word, that is, the word of the reader (learner). What this means is that authors of distance learning texts do not instruct learners, but engage them in the construction of meaning. It is in this context that I make sense of Nietzsche's rhetorical quality of language as a philosophical device that 'does not desire to instruct, but convey to others a subjective impulse and its acceptance' (Nietzsche in Bingham, 1998:231). In other words, we cannot use language without entering the play of mediation and engagement where authors in distance learning entertain and create spaces through their words for multiple layers of sometimes competing meanings.

A dialogic theory of language according to Bakhtin (1981) perceives learners as meaning makers who bring their own ways of knowing to pedagogy. Meaning is also determined in part by the social context in which it is uttered and by the ideological forces of a particular time and place. By implication in distance learning, meaning should be 'mediated' through activities in the texts which engage and intermingle with the virtual voices of learners. It is in this regard that Bakhtin (1981:232) asserts the following about a dialogic theory: 'The word in language is half someone else's. It becomes one's own only when the speaker (teacher) populates it with his (her) own intention, his (her) own accent ...'.

The upshot of the above explanation of a dialogic theory of language is that activities in distance learning should encourage learners to make alternate interpretations; to provoke them to enact a dialogue with the authors (teachers), referred to by Moore (1990) as a 'transaction'.

What should such a notion of dialogue (or dialogical transaction) entail? Dialogue is often mistakenly equated with discussion. Following Schein (1993), discussion often leads to dialectics, which results in a debate and resolution that is usually accomplished by beating down the opposition. Instead, dialogue 
will emerge. Dialogue is a space of deep thinking, where there is nothing to prove, where well worn ways of thinking and being can be let go of. In a dialogue there is nothing to be solved and nothing to be defended (Isaacs in Qualters, 1995:50).

This notion of dialogue is constituted by two important philosophical apects. Firstly, if nothing in a dialogue needs to be 'solved' and 'defended', then the potential of confrontation is ruled out. In this way, the possibility for politeness and mutual trust is enhanced in order to arrive at new ways of thinking and acting. Secondly, dialogue as a 'creative process' implies that the procedure lends itself to an ever-evolving process of deep thinking and the free flow of meaning 'where there is nothing to prove'. Such a dialogue is incomplete and the language leaves itself open to further revision and alternate interpretations. A notion of dialogue between teacher (author) and learner as espoused above can bring about learner-centredness in distance pedagogy in the following ways:

Mutual trust and politeness in the dialogue between teacher and learner at a distance implies that teachers have to expand their selfawareness in order to engender new ways of thinking and acting such as developing greater empathy and sensitivity to the concerns of learner needs.

(2) The dialogical transaction of a free flow of meaning between teacher and learner underscores both agents' commitment to cooperative learning. The teacher and learner at a distance establish a level of intimacy and comfort in order to acquire a sense of each other's perspectives and interests.

Hence, effecting learner-centredness through distance learning lies in the implementation of a dialogical transaction which is supported by a dialogic theory of language. Such a theory views dialogue as a discourse of teachers' self-awareness to engender empathy and sensitivity to the concerns of their learners, as well as a sense of each others' perspectives regarding learning styles, teaching methods, academic preparation and learner resources. Learners become participants in the dialogue and engage with the words of the author (teacher) to create further meanings. Bakhtin's dialogic theory of language reintroduces the power of dialogue as transactions between teachers and learners within distance learning materials. It is this notion of a dialogical transaction which extends to a learner-centred pedagogy within distance learning.

\section{LEARNER-CENTRED PEDAGOGY WITHIN DISTANCE LEARNING: A MOMENT IN MY PRAXIS}

What constitutes learner-centred interactive distance learning materials? The National Commission on Higher Education (NCHE) Report states the following regarding studentcentred distance learning materials:

The use of well-designed learning resources, with which students can interact at an appropriate pace, enables academic staff to shift their emphasis away from lecturing towards curriculum and course design, tutor training, assessment, quality assurance and promotion ... If implemented successfully, 
this approach should enable academic staff to lead and direct well-designed learning environments for larger and more heterogenous groups of students (NCHE, 1996:119-120).

In the Glossary of the NCHE Report the following definition of learner-centred distance learning materials is given:

[Learner-centred distance learning is] ... the increasing use of a variety of media, methods and mechanisms to meet the different and divergent needs of learners in a rapidly changing educational situation, with diminishing dependence on face-to-face communication, and growing reliance on welldesigned interactive study material, the implementation of computer-based and audio-visual instruments and programmes, and diversification in the manner and location of educational guidance and support offered to learners by teachers (a notion signalling the increasing collapse of the traditional sharp distinction between contact and distance education.) (NCHE, 1996:273).

Implicit in the above descriptions of learner-centred distance learning materials is a dialogic theory of language which opens up possibilities such as the use of 'well-designed interactive study materials' and other educational resources 'to meet the different and divergent needs of learners in a rapidly changing educational situation'. My claim is that 'diversification' in the provision of educational resources and support offered to learners by teachers - as well as academic staff shifting 'their emphasis away from lecturing towards curriculum and course design, tutor training, assessment, quality assurance and promotion' - provide the key to what is meant by learner-centred distance learning. In other words, practices such as a diverse, flexible approach to education, providing learner support, ensuring quality, using a 'variety' of educational resources, meeting diverse educational needs, preparing 'different', that is, the widest possible range of learners, are constituted by a rationale which encapsulates dynamism and flexibility. These features have generally been lacking in the design, development, production and delivery of print-based materials (NCHE, 1996:120-121). Moreover, the Green Paper on Higher Education Transformation (GP) endorses the NCHE's recommendation to develop quality and cost-effective learnercentred distance learning materials which are well-designed to meet the challenges of 'greater access and enhanced quality in the context of resource constraints and a diverse student body' (1996:16). For these reasons, it seems feasible to use and develop an instructional design strategy which draws on the complexities of design associated with a dynamic, flexible approach underscored by a dialogic theory of language.

Before moving on to a discussion of how a dialogic theory of language can guide a system of instructional design, I shall first explain how one can provide 'greater access' to diverse learners through distance learning using my own experience in designing an honours course in educational studies. The course was organised in such a way that it offered learners a core body of concepts complemented by relevant and critical readings. It also included activities (reflective and written assignments) that were designed to demand use of critical reflection and rethinking of knowledge and the production of learners' own and shared meanings. Learners through engaging with the text were not only encouraged to make analytical summaries of the selected readings to ensure a basic understanding of the texts, but also to interpret these same texts relevant to their own social and every day life experiences. They were then challenged to critically appropriate and reconstruct their 
understandings and interpretations of these readings with respect to change and transformation in their society. In a different way, learners were engaged critically in activities. The understanding of knowledge which underlines such an approach to meaning making, is that knowledge is not complete, predetermined and discipline related, but rather, continuous and constructed in specific social and historical settings.

I started writing the course by discussing the conceptual underpinnings of issues about knowledge in the curriculum, in particular the diversity of ways in which knowledge within the field of education and educational research is produced. I then focussed on those conceptual thinking patterns that would engender a critical understanding and approach to educational studies. I continuously related what appeared to be abstract, theoretical and methodological perspectives in education with situational examples where these perspectives were at play and embodied in every day life situations After the presentation and exposition stages, learners as individuals were asked to engage critically in the reading of knowledge and knowledge formation as constructed and applied in the world. Finally learners were provoked to reflect through self-debate and questioning on these issues about knowledge in selected readings and how such issues relate to their own common understandings and ways of seeing the world. My teaching strategy through the writing of the distance learning text was based on the understanding that we have to know content (what knowledge is), how we reflect on how we come to know, and why we have to know. These are the essential underpinnings of a dialogic theory of language.

The assessment of the course (content, approach and methodology used) was done at the end of the course. I conducted a focus group interview with the learners on the activities, readings, assignments and topics covered in the course with the aim of improving the content, presentation and the relevance of the topics included in the curriculum. The general response of the group to the curriculum was encouraging. They valued the learnercentred approach to distance learning because it not only challenged their own assumptions about knowledge and knowing, but also engaged them critically with the diverse constructions of knowledge through different readings. They seldom relied on my analytical summaries of the texts, and instead, mediated their diverse critical perspectives through constructions and reconstructions of meanings were unknown even to me. Learners liked the self-reflective activities in the text for the reason that it created conditions for critical inquiry. This learner-centred approach to distance learning opened up possibilities for learners to question, reflect on, challenge and reconstruct knowledge constructs. Regarding the assignment learners had individually to produce at the end of the course, they stated that, although it was 'difficult to analyse their readings' rationally and systematically, the opportunities to reflect, rethink, construct and reconstruct their own meanings contributed to their ability to 'understand educational developments in a period of change in South Africa in a critical manner'.

Finally I appreciated the students' evaluation of the course content and methodology since they provided me with more possibilities to interpret, construct and rethink knowledge and knowing in an ongoing manner. Their positive yet critical feedback offered me more possibilities to chart out my own future pedagogical practice not only in relation to the theory and practice of education in distance learning, but also to be open to the many educative voices in my own society - to remain learner-centred. In essence, 'greater access' to distance learning implies that individuals through distance learning materials can make sense of their own worlds, to determine their own interests, both individually and collectively and express their own views in relation to social issues. In this way, distance 
learning offers to engage (learners as equals in) everyday life that would provide substantial elements for reflection, constructing and reconstruction of more liberatory pedagogical practices.

I shall now look at instructional design and how it can be shaped by a dialogic theory of language. In this way I also hope to give conceptual clarity to some of my experiences with the design and development of distance learning materials.

\section{DYNAMIC AND FLEXIBLE INSTRUCTIONAL DESIGN}

Literally, to design something has to do with shaping, creating, fashioning, moulding, etc. This suggests that design is an action concept, that is, a practice. According to Johnson (1989:3), instructional design involves organizing and 'using tools of the mind and tools of learning, to improve the conduct of education and training ... (it) involves thinking creatively about teaching and learning'. Moreover, instructional design 'provides a set of tools that allow us to maximise individual learning potential ... (and) to meet learner needs' (Johnson, 1989:4). Kember and Murphy (1995:104) hold that instructional design not only transmits knowledge and knowledge structures, but is aimed at accomplishing conceptual change in learners. In this way, instructional design draws on a dialogic theory of language; it engages learners dialogically and allows them to construct alternate meanings through their interaction with distance learning materials, more specifically, the words of the author (teacher).

Furthermore, instructional design 'is a creative, flexible, dynamic process; it is not ruledependent, but fluid and responsive ... an evolving (adaptable) discipline' (Johnsoln, 1989:14). That instructional design is a 'creative, flexible, dynamic process' suggests that its foundations are not derived from any single discipline, but rather, 'call on a wide range of perspectives on learning and human behaviour as well as how that information can be creatively combined within a broader social and organisational context' (Johnson, 1989:6). In this sense, instructional design uses a dialogic theory of language whereby learners bring their own ways of knowing to the distance learning texts and construct meaning within the social context of the author's (teacher's) words.

The question arises: How should ID shape distance learning materials to ensure that a dialogical transaction occurs between author and learner? Firstly, a dialogic theory of language engenders an understanding that distance learning texts should get learners to imagine that they are in a two-way conversation or dialogue with teachers (authors). This implies that there exists an interplay of ideas (between learner and teacher) stated or uttered in the distance learning text. The words of the texts should be formulated and constructed in such a way that it embodies an awareness of the learner and also anticipates a future response. No wonder ID has a situational evaluation component (diagnosis) which involves doing the following:

- Analyse needs/problems through identifying discrepancies between desired and actual learning;

- Analyse constraints and resources such as identifying the scope of the need/problem, whether related to the curriculum, instruction, course, module and/or lesson;

- Analyse target population through determining learner characteristics 
(educational background, age, ability, need for motivation, present skill levels, number of students, geographic location, and culture) and learner differences in (cognitive style, aptitude, learning style, perception, language ability, etc.) (Tennyson, 1995:124).

By doing the situational analysis, authors (teachers) can make sure that the words of the distance learning texts pose questions to learners that they might respond to. Learners, through engaging with the distance learning texts, critically reflect on the authors' words, construct meaning and call into being new questions which would further give different nuances to their understanding of the words. Through their critical engagement, that is, through questioning, interrogating and elaborating on the written words, they become participants in a dialogical transaction.

Secondly, a dialogic theory of language shapes ID in such a way that learners are provoked to see how concepts through the written word are contextual and not neutral and impersonal. In other words, ID should build into the texts activities that make learners reflect on the contextual meanings of words. In this way learners will be prepared for further activities that show how meanings connect with, and are relevant to, concrete social situations. This view of contextual meanings is vindicated by (McLaren, 1991:10) for whom 'all knowledge is relational and can only be understood within the context of production, its distributions, and the way it is taken up by different individuals and groups ... Put differently, meanings do not comprise a universal, value-free body of facts, independent from the understandings of people. Rather, it is produced, located and understood within existing social and cultural formations (Giroux, 1999). In Gramscian terms, culture refers to the production and legitimation of knowledge through the overt and hidden (school) curricula so as to legitimate the hegemonic power of the dominant group thereby marginalising the voices of subordinates. A dialogic theory of language repudiates and challenges forms of power relations which undermine the knowledge constructions of learners through their own experiences, 'their own knowledges'. Accordingly, 'scientific knowledge' and school / academic knowledge do not just represent an immutable body of unquestioning facts, unrelated to the diverse and every day life experiences of learners. Any form of knowledge is context-specific, relevant and emerge 'out of social conventions and sometimes in opposition to them' (McLaren, 1991:10).

Thirdly, meanings in distance learning texts are incomplete constructs which await further participation and use on the part of learners. In other words, meanings cannot just be regarded as final but should be used to 'transform the world' (Freire, 1972). Constructing meanings is also 'about the knowledge and practices that teachers, cultural workers, and students might engage in together and the cultural politics such practices support ... to construct a political vision' (Giroux, 1992:242). I link Giroux's idea of meaning making in order to construct a 'political vision' to the transformative and emancipatory possibilities that a dialogic theory of language in the Freirian sense can achieve. What is significant in Giroux's use of construction of meaning is the link he establishes between meaning making and critical engagement. This implies that knowledge with the fundamental aim of transforming and liberating people is produced through engaging them critically in action; people (educators, learners, and other groups) constitute a collaborative group of critical inquiry through their engagement with distance learning materials. They are different, yet they intersubjectively share and negotiate patterns of meaning in order to broaden the conditions for the production of socially relevant knowledge. In this way, creating spaces through ID to engage learners with distance learning texts establishes possibilities for them 
to become self-critical. Yet, they remain socially engaged, that is, in 'constant dialogue' with others (teachers, community groups, and so on) to address the most pressing social (educational) and political problems of their time (Giroux, 1992).

\section{CONCLUSION}

In this article, my emphasis has been on the use of a dialogic theory of language in designing distance learning materials. I argued that for ID to be dynamic and flexible it has to be oriented towards producing learner-centred course materials. Finally, I showed how a dialogic theory of language can bring about a system of ID that can be used to design interactive distance learning course materials.

\section{REFERENCES}

BAKHTIN, M. 1981. The dialogic imagination. Austin: University of Texas.

BINGHAM, C. 1998. The goals of language, the language of goals: Nietzsche's concern with rhetoric and its educational implications. Educational Theory, 48(2):229241.

DEPARTMENT OF EDUCATION, 1996. Green Paper on Higher Education Transformation, South Africa.

FREIRE, P. 1972. Pedagogy of the oppressed. New York: Continuum.

GIROUX, H. 1992. Border crossing: Cultural workers and the politics of education. New York: Routledge.

GIROUX, H. 1999. Rethinking cultural politics and radical pedagogy in the work of Antonio Gramsci. Educational Theory, 49(1):1-19.

JOHNSON, K. 1989. The foundations of instructional design. In Johnson, K and L Foa (eds), Instructional design: New alternatives for effective education and training. New York: Collier Macmillan.

KEMBER, D. AND MURPHY, D. 1995. The impact of student learning research and the nature of design on ID fundamentals. In Seels, B. (ed) Instructional design fundamentals: A reconsideration. New Jersey: University of Pittsburgh.

MCLAREN, P. 1991. Critical pedagogy: constructing an arch of social dreaming and a doorway to hope. Journal of Education, 173(1):9-34.

MOORE, M. 1990. Recent contributions to the theory of distance education. Open Learning, 5(3):10-15.

NATIONAL COMMISSION ON HIGHER EDUCATION REPORT, 1996. A Framework for Transformation, South Africa. 
QUALTERS, D. 1995. A quantum leap in faculty development: beyond reflective practice. The Professional and Organizational Development Network in Higher Education Journal, 14:43-55.

SCHEIN, E. 1993. On dialogue, culture and organizational learning. Organizational Dynamics, 22:40-51.

TENNYSON, R. 1995. The Impact of the cognitive science movement on instructional design fundamentals. In Seels, B. (ed.), Instructional design fundamentals: A reconsideration. New Jersey: University of Pittsburgh.

WEDEMEYER, C.A. 1971. Independent study. The Encyclopedia of Education, 4:548557. 